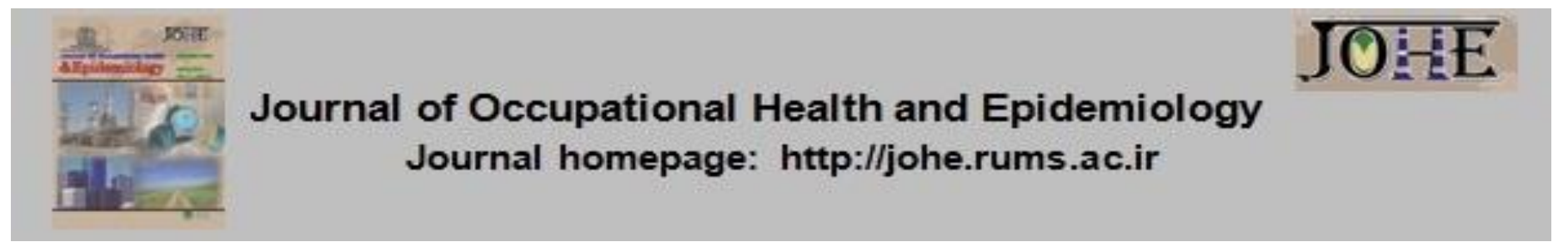

\title{
Predicting the health performance of high school principals based on spirituality in the workplace, Tabriz, Iran (2018-2019)
}

\author{
Samereh Moghaddam Hosseini ${ }^{1}$, Zarrin Daneshvar ${ }^{2 *}$, Asadollah Khadivi ${ }^{3}$, Behnam Talebi ${ }^{1}$ \\ 1- PhD Student, Department of Educational Administration, Tabriz Branch, Islamic Azad University, Tabriz, Iran. \\ 2- Assistant Prof., Department of Educational Administration, Tabriz Branch, Islamic Azad University , Tabriz, Iran. \\ 3- Assistant Prof., Educational Administration, Department of Educational Sciences, Farhangian University, Tehran, Iran.
}

\section{Article Info}

* Corresponding author:

Zarrin Daneshvar,

E-mail:

zarrindaneshvar@gmail.com

\section{Article history}

Received: Jul, 2019

Accepted: Sep, 2019

10.29252/johe.8.3.163

Print ISSN: $2251-8096$ Online ISSN: 2252-0902

Peer review under responsibility of Journal of Occupational Health and Epidemiology
Citation: Moghaddam Hosseini S, Daneshvar Z, KhadiviA, Talebi B. Predicting the health performance of high school principals based on spirituality in the workplace, Tabriz, Iran (2018-2019). JOHE 2019; 8(3):163-70.

\begin{abstract}
Background: Providing favorable services associated with students' behavior and health care is one of the most important tasks of school principals, and the health performance (HP) of schools is influenced by the organizational factors, such as spirituality in the workplace (SW).The purpose of this research is to predict the HP of school principals based on SW.

Materials and Methods: In this descriptive study, all high school principals in Tabriz $\left(\mathrm{N}_{=}=800\right)$ during 2018-2019 academic year were listed. Of these, 258 principals were selected through stratified random sampling in terms of location of schools. Data collection was performed using, the questionnaires of managers' HP and SW, as well as its components, including meaningful work (MW), sense of community (SOC), and the alignment of organizational values (AOV). Data were analyzed using path analysistest using PLS software.

Results: The results of structural equation modeling revealed that the HP of school principals based on SW and its components was predictable. The predicted coefficient (adjusted R2)was 0.49. Furthermore, the results showed that the path coefficients of latent variables were significant $(P<0.001)$.

Conclusion: It is required to have a proper spiritual environment and pay attention to spirituality in the school workplace in order to improve the HP of school principals to provide good health services to students.
\end{abstract}

Keywords: Health, Student Health, Work

\section{Introduction}

School administrators, as government representatives, play an important role in promoting the quality of education and educational justice [1]. From the government perspective, their performance plays a decisive role in ensuring the effectiveness of schools [2]. It is important, therefore, to enhance the school performance and ensure the quality of its services [3]; thus, school assessment is increasingly seen as potential leverage [4]. On the other hand, school performance stems from the activities and characteristics of principals [5], and managers need to have some unique features to enhance the school performance [6].

There is growing recognition that health and health care at school can significantly affect children health [7]. Knauer et al. stated: "Increased funding, school health service monitoring, service integration, and interagency collaboration are strategies that could improve the delivery of health services at schools" [8]. Schools offer the potential to reach children at an early age, just as they are developing important attitudes and behaviors that may influence their health in the future [9]. Schools 
act as ideal interventional settings as they can reach almost all children during critical periods of development [10]. Adolescence is characterized by dramatic physical and psychological changes, as well as alterations in social perceptions and expectations. The emergence of health risk behaviors during this period has important consequences for physical and mental health, as well as for emotional well-being both during this life phase and later [11]. The school is a key context for young people development, ranging from the breadth and depth of their intellectual capital andpeer influence nature to their wellbeing [12].

Failure to meet school goals and numerous criticisms at various national and local levels of education indicate poor performance of schools and high schools, especially in the final output, are not desirable and acceptable [13]. Therefore, it is necessary to increase the effectiveness of key factors on performance [14]. "Performance measurement is one of the most important strategic processes" [15]. "Performance is defined as the extent to which a person fulfills duties assigned to him/her over a specified period" (16). "Organizational performance is considered as the method by which to carry out missions, tasks, as well as organizational activities and their results" [17].

Workplace spirituality research emerged as a response to care provider determination in order to maintain a healthy and productive work environment [18]. "Novel management methods and new organizational systems are necessary to keep up with this emergent context. Spirituality in the workplace states that personnel seek nourishment for both the extents, i.e. their vertical and horizontal, and extents of their spirituality at work. It is about people and organizations perceiving work as a spiritual pathway, as a chance to cultivate and to do something for humanity. It is all about care, empathy, and sustenance of others, about truthfulness and persons being truthful to themselves and others, endeavoring to live their values more effusively while performing their work" [19]. The results of Milliman et al. research in the study of Southwest Airlines showed that spiritual values can positively impact both profitability and employee attitudes in organizations [20]. The concept of spirituality in the workplace is analyzed as a three-dimensional component, viz., individual level, group level, and organization level by Milliman et al. Spirituality mainly focuses on the meaningful work, sense of community, and the alignment of organizational values [21].

A sense of community and meaningful work are the most important dimensions of workplace spirituality in health care [22]. The sense of community is about the interaction and relation among people, and the community stands for a strong bond between individuals [23]. Meaningful work refers to the interaction of work task and the life purpose, as well as the personal inner feelings towards work meaning and intention [24]. The alignment of organizational values, the third dimension of workplace spirituality, is experiencing a strong sense of convergence between the individual values of employees with the mission and values of the organization. This component of spirituality in the workplace involves the interaction of employees with a larger organizational purpose [25]. Ashmos and Duchon argue that aligning with the values of the organization means individuals believe that managers and employees in the organization have pertinent values and strong conscience and that the organization is concerned with the welfare of employees and their solidarity [26]. In agreement with these findings, Chappell suggests shared values and purpose senses can turn a company into a community, where daily work takes on a deeper meaning and inner satisfaction (27).Whether applying, enabling and incorporating spirituality practices in organizations increase productivity or profitability is a very complex and controversial issue [27].

Some researchers, supporting this position, point out that there may indeed be ethical pitfalls and moral concerns in the research question of whether enabling or incorporating spirituality at work results in better organizational performance or profitability [26, 27]; they argue that spirituality can be used to improve organizational performance. Research results have shown that the characteristics of managers $[5,28]$ and spirituality in the workplace [29-31] affect their performance. In India, Mahipalan \& Sheena in a study on high school teachers emphasize that spirituality in the workplace leads to an optimal level of human performance(32). Masciet al. by examining the effect of school size, managerial characteristics, and school management practices on the teaching performance in Italian secondary schools, found out that the characteristics and activities of managers play a vital role in school performance [28]. Milliman et al. by studying the role of spirituality in the workplace, job involvement and the desire to stay in the organization, concluded that spirituality in the workplace has an important role in increasing both [29]. Faro stated that organizational performance is predicted by a sense of community in primary health care services [33]. Pawar Badrinarayan research revealed that workplace spirituality has a positive relationship with emotional, psychological, social, 
and spiritual well-being [34]. The results of Soha et al. research indicated that work influence factors are significant in organizational performance at secondary school [24]. Joelle and Coelho's research revealed that job resourcefulness appears to be a better mediator in the relationship between spirituality at work and individual performance [35]. Garg investigated the mediating effect of employee commitment, employee engagement, and work motivation in the relationship between workplace spirituality and organizational performance in the Indian context. Results showed that organizational commitment (affective and normative), employee engagement, and work motivation partially mediate the relationship [36]. Besides these, studies have also shown that there is no relationship between spirituality in the workplace and workforce performance [37-39]. On the other hand, based on the literature review, the study of this problem has not been available to researchers in the field of health performance of schools' principals. Based on theory and research literature, this research aimed to determine the role of SW and its components inHP in Tabriz educational districts' high schools and answer the question of "what is the role of SW and its components in high school principal's HP?"

\section{Materials and Methods}

The population of this correlational research consisted of all public and private high school principals of Tabriz $(n=800)$ in the 2018-2019 academic year. According to Krejcie and Morgan's table, using a stratified random sampling method at first and lottery and simple random sampling method in the second step, 258 principals we reselected. The sample size in the structural equations was set at 10 for each latent variable and at least 200 for the sample [40]. Accordingly, the sample size was desirable to generalize results. Principal participation criteria in the research were to have at least three years of management experience in the current position and be informed and agreed to participate. Data collection was done through two questionnaires.

1. Spiritual at workplace questionnaire (Milliman et al., 2003): The SW questionnaire measured the degree to which the individual experiences work spiritualityinthe workplace. In this research, Milliman et al. questionnaire has been designed to be used for measuring organizational spirituality. It has 18 questions and 3 components, including MW (items 1 to 5), SOC (items 6 to 11), and AOV (items 12 to 18). The 18-item questionnaire displayed Wagner et al. face, content, and construct validity in previous Kinjerski's research. In addition, studies by Kinjerskiand Skrypnek as well as Wagner and Gregory revealed that the Cronbach's alpha for the SW construct ranged from 0.91 to 0.93 . Wagner et al. showed that Cronbach's alpha for the SW construct was 0.92 [18]. The Cronbach's alpha for the WS construct ranged from 0.88 to 0.91 . The Cronbach's alpha for the SW construct in this study was 0.91. Furthermore, the Cronbach's alphas for the components of SWwere 0.88 for MW, 0.9 for SOC, and 0.87 for AOV. The answers to the questionnaire were five degrees from 1 to 5. Accordingly, the minimum score was 18 and the maximum score was 90 .Also,based on the result of multiplying the number of items by the average score of the item, the middle score was 54 . The middle score for MW, SOC, and AOV, was 15, 18, and 21, respectively.

2. Principal performance in school health services questionnaire (Moghaddam Hosseini \& Talebi, 2018): In this research, the principal performance in school health services data were obtained from this questionnaire. This questionnaire is a 14item self-report scale. The answers to the questionnaire were five degrees from 1 to 5 . Accordingly, the minimum score was 14 and the maximum score was 70 . The middle score was 42 based on the result of multiplying the number of items by the average score of the item. Content and face validity of this questionnaire was approved(2);content validity was used by 12 experts, and CVR of 0.87 and CVI of 0.84 were calculated. In this research, the Cronbach's alpha for the HP construct was 0.89 .

The research question for the current study was"is principal HP predictable at high schools based on their WS and components?" In order to analyze the data, the determination coefficient was estimated at the significance level of 0.05 using the structural equation model with PLS software. Ethical considerations, secrecy, and confidentiality of principals' information have been regarded in this research. 


\section{Results}

The research results are presented in two parts, i.e. descriptive (demographic characteristics and descriptive statistics of variables) and hypothesis analysis.

Based on the sample demographic characteristics of high school principals surveyed in Tabriz in the academic year 2019-2018, most principals are aged $45-55(37 \%)$ and35-55(71\%). In addition, 46\% were men, and the rest were women. Most

managers $(70 \%)$ have master degrees $(n=178)$, $25 \%$ bachelor degrees $(n=66)$ and $5.43 \%$ PhDs $(n=14)$.

According to the data in Table 1, the mean HP of school principals is $56.3 \pm 7.22$, and principals have high HP. The mean of SW is $74.48 \pm 7.92$ that is higher than the medium. Furthermore, the status of principals in the SW components is higher than the medium.

Table 1: Descriptive indicators of variables in Tabriz high school principals in the academic year of 2018-2019

\begin{tabular}{lccc}
\hline \multicolumn{1}{c}{ Variable } & Min & Max & M \pm S.D \\
\hline Health performance & 32.00 & 70.00 & $56.3 \pm 7.22$ \\
\hline Alignment of organizational values & 7.00 & 35.00 & $28.81 \pm 5.49$ \\
\hline Sense of community & 6.00 & 30.00 & $24.62 \pm 4.83$ \\
\hline Meaningful work & 5.00 & 25.00 & $18.51 \pm 6.25$ \\
\hline Spirituality in the workplace & 53.00 & 90.00 & $74.48 \pm 7.92$ \\
\hline
\end{tabular}

Based on the results of the PLS regression test (Table 2), the path coefficients according to the Tvalue plus the $\mathrm{P}$-value was significant in the $\mathrm{MW}$, AOV, SW, and SOC. The MW, AOV, SOC, and
SW are effective on the HP of school principals. Model fit indices show that both measurement models, the structural and the total models of the research, have a good fit.

Table 2: Results of the partial least squares regression in performance prediction and model fit

\begin{tabular}{|c|c|c|c|c|c|}
\hline Model fit & Report & AOV & MW & SOC & SW \\
\hline \multirow{4}{*}{ Measurement } & CR & 0.86 & 0.94 & 0.91 & 0.88 \\
\hline & AVE & 0.52 & 0.56 & 0.8 & 0.88 \\
\hline & Path Coefficient & $0.49^{\star *}$ & $0.88^{\star *}$ & $0.76^{\star \star}$ & $0.7^{\star \star}$ \\
\hline & Total Effect & $0.49^{\star \star}$ & $0.88^{\star *}$ & $0.76^{\star \star}$ & $0.7^{\star \star}$ \\
\hline \multirow{3}{*}{ Structural } & R square adjusted & \multicolumn{4}{|c|}{0.49} \\
\hline & Q2 & 0.32 & 0.65 & 0.46 & 0.25 \\
\hline & $T$ & $5.92^{\star \star}$ & $40.2^{\star \star}$ & $25.27^{\star \star}$ & $21.3^{\star \star}$ \\
\hline \multirow{2}{*}{ Total } & GOF & \multirow{2}{*}{\multicolumn{4}{|c|}{$\begin{array}{l}0.37 \\
0.06\end{array}$}} \\
\hline & SRMR & & & & \\
\hline \multicolumn{6}{|l|}{$\alpha<0.001^{* *}$} \\
\hline
\end{tabular}

Chart 1 shows the T-values of each item in relation to the variables, as well as the path coefficients. Accordingly, the T-value in all items, as well as all variables, is above 1.96 and significant.Based on Chart 1, the MW, AOV, SW, and SOC havehad aneffect on the HP $(P<0.001)$.

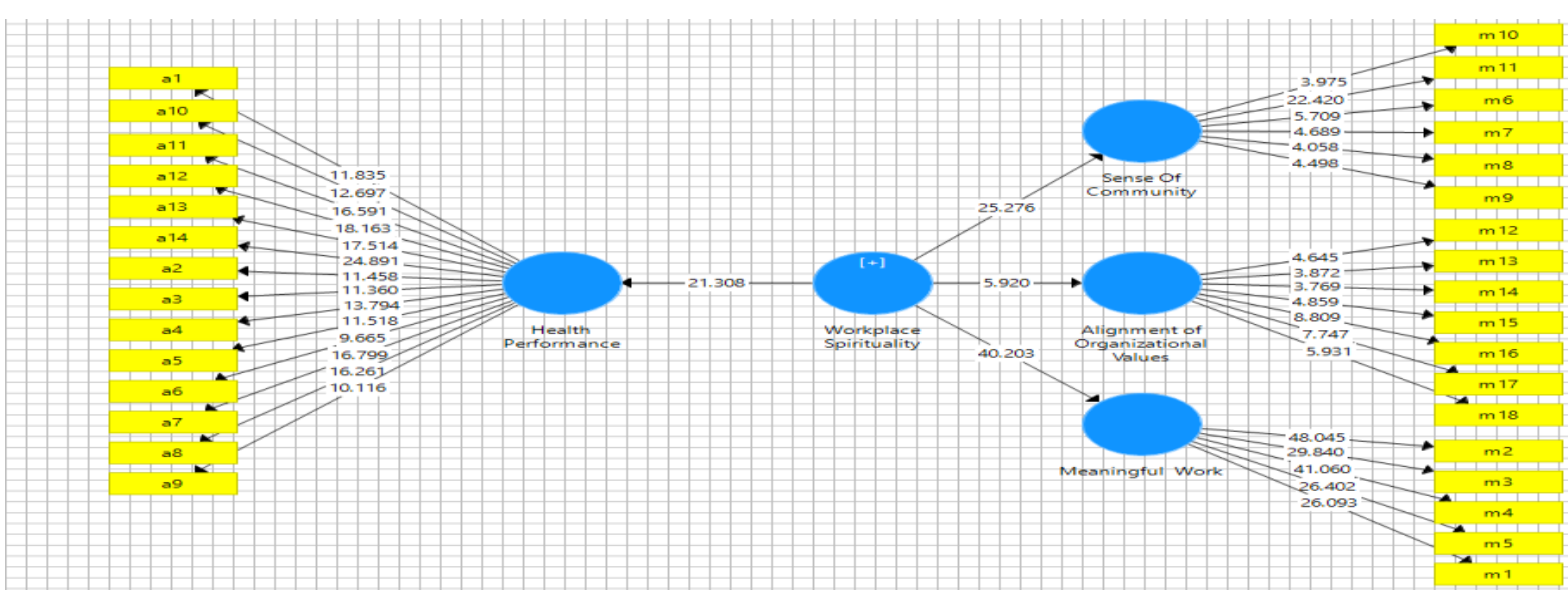

Figure1: T-values of the Health Performance Prediction based on Spirituality in the Workplacein Tabriz high school principals in the academic year of 2018-2019

Note: $\mathrm{a} 1$ to $\mathrm{a} 14$ are HP items, and $\mathrm{m} 1$ to $\mathrm{m} 18$ are SW items. 
Chart 2 shows the path coefficients and the determination coefficients of each variable in the HP forecast. According to Chart 2, the MW, AOV, SW, and SOC have a direct impacton the HP adjusted $\mathrm{R}$ square as 0.498 . Therefore, $49 \%$ of the school principal's HP changes are predictable based on their SW.

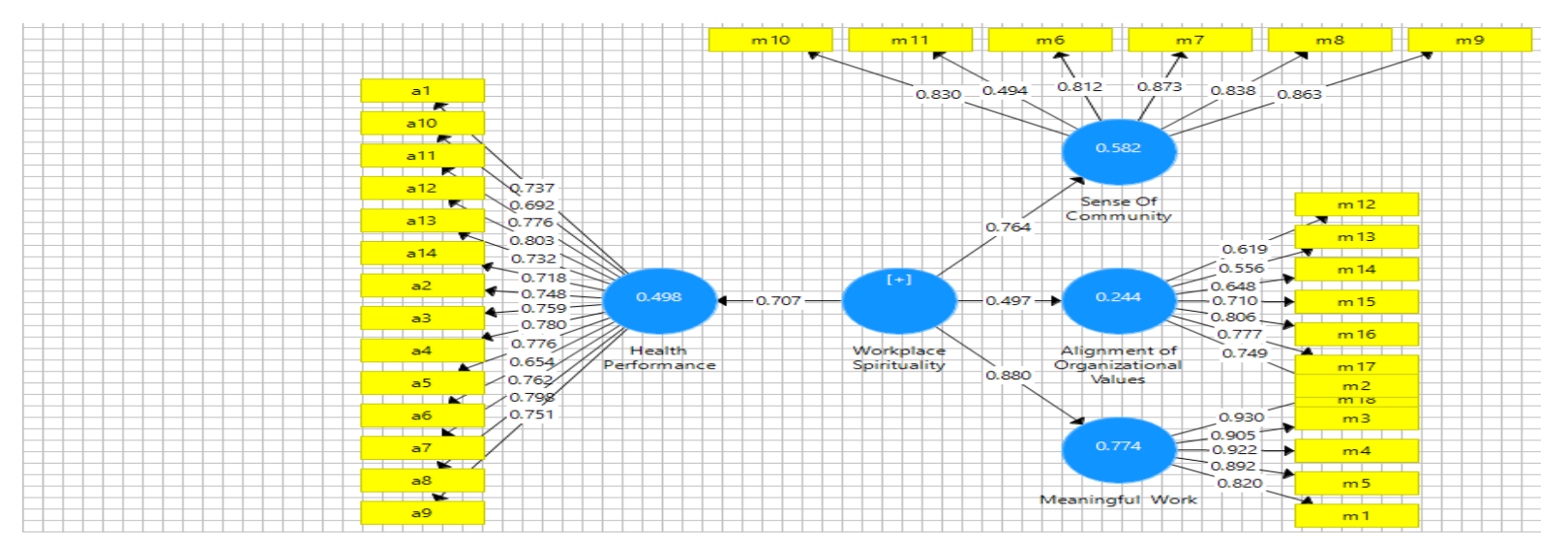

Figure2: Path coefficient of the Health Performance Prediction based on Spirituality in the Workplacein Tabriz high school principals in the academic year 2018-2019

Note: a1 to a14 are HP items, and $\mathrm{m} 1$ to $\mathrm{m} 18$ are SW items.

\section{Discussion}

The results of this study showed that spirituality at workplace, as well as the components of values and meaningful work, can explain the health performance of high school's principals in Tabriz. However, the component of sense cannot explain it.

These results are consistent with Norouzi et al.[41], Wagner [18], Sachdeva [19], Pirkola et al. [22], Ashmos \& Duchon [26], Karakas [27], Milliman et al. [29], Azad Marzabadi et al. [31], Mahopalan [32, 42], Masci et al. [28] Faro [33], Pawar [34], Soha [24], Joelle [35], and Garg [36]. It is alsoin line with the results of Neal [37], Sintaasih Desak [38), Sony, and Mekoth [39] research.

$\mathrm{SW}$ is a form of human potential that has a crucial role in promoting performance [43, 44], voluntary career behavior [45-47], team learning [48], responsible leadership and decision-making [49], organizational commitment [50, 51], job satisfaction [47, 50], well-being [34], that can also promote performance. Therefore, its promotion is supported [49].

Better spiritual condition improves performance [44] because the specific working conditions and secondary school nature, especially in the field of student health, are influenced by cultural and social factors. A school is a technical-social system, where the performance of principals is more consistent with the culture, values, spirituality, social expectations, and student demand. In explaining this finding, we can say it is important to pay attention to cultural and social foundations in schools. The important factors that distinguish the education and the health systems from the industry and economics systems deserve more attention.

In the workplace, spirituality is a means of consolidating the meanings, goals, ideals, as well as individual and organizational plans to realize and contribute to the coherence of ongoing activities, programs, and operations in line with the organizational vision. Spirituality in work can be more motivating to facilitate the implementation of affairs optimally.

A key limitation of this study was the limited scope to evaluate school principal health performance. Thus, it is suggested that future studies investigate different domains of school principals' performance and their possible interactions altogether. Based on the results, future researchers are recommended considering the limitation of this study concerning the non-availability of schools promoting health and other education levels.

\section{Conclusion}

To explain the findings, one could say that spirituality in the workplace can enhance workforce performance through motivation, self-esteem, responsibility, as well as the association of current activities with supernatural meanings. In this regard, dealing with human life and paying attention to the sensitivity of students' health in schools, as well as preventing their risk of various diseases or physical and psychological risks, are more important. Thus, it can lead to improving the productivity of schools in providing health to students. 


\section{Acknowledgement}

The authors would like to thank Tabriz branch of Islamic Azad University, Tabriz educational districts, and Tabriz high school principals for their cooperation in this research.

Conflict of interest: None declared.

\section{References}

1. Madariaga L, Nussbaum M, Burq I, Marañón F, Salazar D, Maldonado L, et al. Online survey: A national study with school principals. Comput Human Behav 2017; 74:35-44.

2. Moghaddam Hosseini S, Talebi B. A Partial Least Squares Path Model of Principals' Performance in School Health Services Based on Spiritual Intelligence in Tabriz Female High Schools. International Journal of School Health 2018; 5(3):e77217.

3. Schildkamp K, Visscher A. Factors influencing the utilisation of a school self-evaluation instrument. Studies in Educational Evaluation 2009; 35(4):150-9.

4. Chen $\mathrm{H}, \mathrm{Su} Y$, Zheng $\mathrm{Q}$, Li L. Towards an operationalized and effective school selfevaluation system: An ongoing action research study in Chinese secondary schools since 2011. Studies in Educational Evaluation 2019; 60:11729.

5. Tavares PA. The impact of school management practices on educational performance: Evidence from public schools in São Paulo. Econ Educ Rev 2015; 48:1-15.

6. Piaw CY, Hee TF, Ismail NR, Ying LH. Factors of Leadership Skills of Secondary School Principals. Procedia Soc Behav Sci 2014; 116:5125-9.

7. Lear JG, Barnwell EA, Behrens D. Health-care reform and school-based health care. Public Health Rep 2008; 123(6):704-8.

8. Knauer H, Baker DL, Hebbeler K, Davis-Alldritt L. The Mismatch Between Children's Health Needs and School Resources. J Sch Nurs 2015; 31(5):326-33.

9. Mclsaac JD, Read K, Veugelers PJ, Kirk SFL. Culture matters: a case of school health promotion in Canada. Health Promot Int 2017; 32(2):207-17.

10. Storey KE, Montemurro G, Flynn J, Schwartz M, Wright E, Osler J, et al. Essential conditions for the implementation of comprehensive school health to achieve changes in school culture and improvements in health behaviours of students. BMC Public Health 2016; 16(1):1133.

11. Shinde $S$, Pereira $B$, Khandeparkar $P$, Sharma A, Patton G, Ross DA, et al. The development and pilot testing of a multicomponent health promotion intervention (SEHER) for secondary schools in Bihar, India. Glob Health Action 2017; 10(1):1385284.
12. Rathmann K, Herke MG, Hurrelmann K, Richter M. Perceived class climate and school-aged children's life satisfaction: The role of the learning environment in classrooms. PLoS One 2018; 13(2):e0189335.

13. Rezaee B, Tarin H. A meta-analysis on researchs effective factors on the performance of school principals. Journal of School Administration 2017; 5(2):193-215.

14. Nazari R, Vaziri M, Adli F. Parent assessment of the performance of public and nongovernmental school staff based on the customer-centric dimensions of SERVQUAL model. Journal of New Thoughts on Education 2013; 9(2):151-74.

15. Bakhshi E, Gharagozlou F, Moradi A, Naderi MR. Quality of work life and its association with job burnout and job performance among Iranian healthcare employees in Islamabad-e Gharb, 2016. Journal of Occupational Health and Epidemiology 2019; 8(2):94-101.

16. Shikhakbari Z, Ziaadini M. The mediator role of social phobia in the association between resiliency and job performance among nurses of Ali Ibn Abi Taleb hospital of Rafsanjan, Iran (2017). Journal of Occupational Health and Epidemiology 2018; 7(4):227-32.

17. Taboli H, Ayagh G, Bastami R, Hakimi I. Modeling the relationship between organizational culture, clinical governance, and organizational performance: A case study of Tamin Ejtemaee hospitals in Mazandaran Province, Iran. Journal of Occupational Health and Epidemiology 2014; 3(4):197-205.

18. Wagner JIJ, Brooks D, Urban AM. Health Care Providers' Spirit at Work Within a Restructured Workplace. West J Nurs Res 2016; 40(1):20-36.

19. Sachdeva G. Impact of Spirituality in Management: A Review. In: Mishra D, editor. Science and Spirituality for a Sustainable World: Emerging Research and Opportunities. 1st ed. Hershey, United States: IGI Global; 2019.

20. Milliman J, Ferguson J, Trickett D, Condemi B. Spirit and community at Southwest Airlines. Journal of Organizational Change Management 1999;12(3):221-33.

21. Milliman J, Czaplewski A, Ferguson J. Workplace spirituality and employee work attitudes. Journal of Organizational Change Management 2003; 16(4):426-47.

22. Pirkola H, Rantakokko $P$, Suhonen $M$. Workplace spirituality in health care: an integrated review of the literature. J Nurs Manag 2016; 24(7):859-68.

23. Duchon D, Plowman DA. Nurturing the spirit at work: Impact on work unit performance. Leadersh Q 2005; 16(5):807-33.

24. Soha HM, Osman A, Salahuddin SN, Abdullah $S$, Ramlee NF. The Relationship of Work Influence, Sense of Community and Individual Spirituality towards Organizational Performance. Procedia Economics and Finance 2016; 35:591-6. 
25. Abbaspoor J, Abbaspoor H, Shahbazi Sh. The effect of organizational spirituality and its dimensions on staff loyalty (Case Study: Mehran Education Organization). Journal of Human Resources Management 2018; 7(26):87-110.

26. Ashmos DP, Duchon D. Spirituality at Work: A Conceptualization and Measure. Journal of Management Inquiry 2000; 9(2):134-45.

27. Karakas F. Spirituality and Performance in Organizations: A Literature Review. Journal of Business Ethics. 2010;94(1):89-106.

28. Masci Ch, De Witte K, Agasisti T. The influence of school size, principal characteristics and school management practices on educational performance: An efficiency analysis of Italian students attending middle schools. Socioecon Plann Sci 2018; 61:52-69.

29. Milliman J, Gatling A, Kim JS. The effect of workplace spirituality on hospitality employee engagement, intention to stay, and service delivery. Journal of Hospitality and Tourism Management 2018; 35:56-65.

30. Drakhshanmehr A, Jabbarzadeh Kangsarloei S, Bahri Sales J. Analysis of relationship between ethical leadership and certified public accountants performance with the role of moderating professional ethics. Quarterly Journal of Public Organizations Management 2018; 6(2):149-58.

31. Azad Marzabadi E, Hoshmandja M, Poorkhalil M. Relationship between Organizational Spirituality with Psychological Empowerment, Creativity, Spiritual Intelligence, Job Stress and Job Satisfaction of University Staff. Journal of Behavioral Sciences 2012; 6(2):181-7.

32. Mahipalan M, S S. Workplace Spirituality and Subjective Happiness among High School Teachers: Gratitude As A Moderator. Explore 2019; 15(2):107-14.

33. Albuquerque IF, Cunha RC, Martins LD, Sá AB. Primary health care services: workplace spirituality and organizational performance. Journal of Organizational Change Management 2014; 27(1):59-82.

34. Pawar BS. Workplace spirituality and employee well-being: an empirical examination. Employee Relations 2016; 38(6):975-94.

35. Joelle M, Coelho AM. The impact of spirituality at work on workers' attitudes and individual performance. The International Journal of Human Resource Management 2019; 30(7):1111-35.

36. Garg N. Workplace Spirituality and Organizational Performance in Indian Context: Mediating Effect of Organizational Commitment, Work Motivation and Employee Engagement. South Asian Journal of Human Resources Management 2017; 4(2):191-211.

37. Neal J. Overview of Workplace Spirituality Research. In: Dhiman S, Roberts GE, Crossman JE, editors. The Palgrave Handbook of Workplace Spirituality and Fulfillment. 1st ed.
Switzerland Cham: Palgrave Macmillan; 2018. P.3-57.

38. Sintaasih DK, Manuati Dewi IGA, Mudiartha Utama IW, Mujiati NW. Work spirituality. International Journal of Ethics and Systems 2019; 35(3):306-22.

39. Sony M, Mekoth $\mathrm{N}$. The relationship between workplace spirituality, job satisfaction and job performance. International Journal of Process Management and Benchmarking 2019; 9(1):2746.

40. Habibi A, Adanvar M. Structural equations modeling and factor analysis (LISREL Manual). 1sted. Tehran: Jehad daneshgahi; 2017.

41. Norouzi R, Dargahi Sh, Aeyadi N, Sarhaddi M. The association between workplace spirituality and Job Stress with occupational ethics through mediating role of Job Enthusiasm among nurses in Zahedan City, 2017. Journal of Occupational Health and Epidemiology 2018; 7(1):3-10.

42. Mahipalan M, Sheena, Muhammed S. Examining the Role of Workplace Spirituality and Teacher Self-efficacy on Organizational Citizenship Behaviour of Secondary School Teachers: An Indian Scenario. Vision: The Journal of Business Perspective 2019; 23(1):8090.

43. Joelle M, Coelho A. The impact of a spiritual environment on performance mediated by job resourcefulness. International Journal of Workplace Health Management 2019; 12(4):267-86.

44. Osman- Gani AM, Hashim J, Ismail Y. Establishing linkages between religiosity and spirituality on employee performance. Employee Relations 2013; 35(4):360-76.

45. Haldorai K, Kim WG, Chang HS, Li JJ. Workplace spirituality as a mediator between ethical climate and workplace deviant behavior. Int J Hosp Manag 2019; doi: 10.1016/j.jijhm.2019.102372

46. Ahmadi S, Nami Y, Barvarz R. The Relationship between Spirituality in the Workplace and Organizational Citizenship Behavior. Procedia Soc Behav Sci 2014; 114:262-4.

47. Belwalkar Sh, Vohra V, Pandey A. The relationship between workplace spirituality, job satisfaction and organizational citizenship behaviors - an empirical study. Social Responsibility Journal 2018; 14(2):410-30.

48. Pandey A, Gupta V, Gupta RK. Spirituality and innovative behaviour in teams: Examining the mediating role of team learning. IIMB Management Review 2019; 31(2):116-26.

49. Siddiqi LA, Chick H, Dibben M. Spirituality and its Role in Responsible Leadership and Decision-Making it. In: Savur S, Sandhu S, editors. Responsible Leadership and Ethical Decision-Making (Research in Ethical Issues in Organizations, Vol. 17). 1st ed. Bingley, West Yorkshire, United Kingdom: Emerald Publishing Limited; 2017. P. 63-81. 
50. Fanggidae RE, Suryana Y, Efendi N, Hilmiana. Effect of a Spirituality Workplace on Organizational Commitment and Job Satisfaction (Study on the Lecturer of Private Universities in the Kupang City -Indonesia). Procedia Soc Behav Sci 2016; 219:639-46.
51. Dehaghi MR, Goodarzi M, Karimi Arazi Z. The Effect of Spiritual Values on Employees' Organizational Commitment and Its Models. Procedia Soc Behav Sci 2012; 62:159-66. 